\title{
Reliability Model for Helicopter Main Gearbox Lubrication System using Influence Diagrams
}

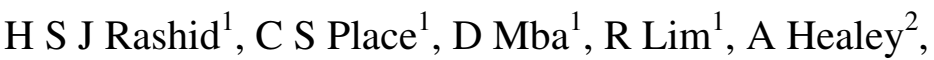 \\ W Kleine-Beek ${ }^{2}, \mathrm{M}^{\mathrm{R} o m a n o}{ }^{2}$ \\ 1. Cranfield University \\ 2. European Aviation Safety Agency
}

\begin{abstract}
This paper presents the development of a model to assess the reliability of helicopter main gearbox (MGB) lubricating systems. The loss of oil from a helicopter MGB will lead to increased friction between components, a rise in component surface temperatures, and subsequent mechanical failure of gearbox components. A number of significant helicopter accidents have been caused due to such loss of lubrication. Current certification requirements for Category A helicopters require that gearboxes which use pressurized lubrication systems must show a capability to continue operation for a period of 30 minutes after suffering a loss of oil.
\end{abstract}

This paper reports on methods for assessing reliability of pressurized MGB lubrication systems. Safety risk modeling was conducted for MGB oil system related accidents and incidents in order to analyse the key failure mechanisms and the contributory factors. As such, the dominant failure modes for lubrication systems and key contributing components were identified. The Influence Diagram (ID) approach was then employed to investigate reliability issues of the MGB lubrication systems at the level of primary causal factors. Early indications show significant benefits from this approach where multiple influences would render alternative approaches overly complex. The ID tool can systematically investigate complex context of events, conditions, and influences that are direct triggers of failures. Within this study, an ID model was introduced to describe the interrelationships between MGB lubrication system failure types. In this way the influence of each of these factors on the overall MGB lubrication system reliability may be assessed.

KEYWORDS: Helicopter main gearbox lubrication; Lubrication system failures; Influence diagrams

\section{INTRODUCTION}

Helicopters are totally dependent on their rotor transmission (RT) systems, which provide the critical links from the engines to the main rotor, tail rotor and ancillary systems. These components are highly loaded and must be manufactured to a high degree of accuracy; the lack of redundancy implies that this is a 'series-chain' system (Astridge 1996, Savage et al 1988).

These RT systems are in turn totally dependent on a functioning lubrication system. The loss of oil from a helicopter Main gearbox (MGB), which is a central system within a helicopter, will lead to mechanical failure of the gearbox components. Current certification requirements for Category A helicopters (large helicopters) require that gearboxes which use pressurized lubrication systems must show a capability to continue operation for a period of 30 minutes after suffering a loss of oil (EASA 2012). However, this has not always been met in service with 
current designs. Many Category A helicopters fly sectors which are over one hour in duration and in the event of a main gearbox loss of oil could require a forced landing over hostile terrain. There have been a number of significant accidents involving the loss of helicopters due to a failure of the Main gearbox lubrication system. A particular case in point was the crash of a large helicopter off the coast of Newfoundland in 2009 (TSB 2010).

This paper explains the use of Influence Diagrams (ID) to supplement the traditional Fault or Event Trees. Analysis of causal factors will often allow a Fault Tree model to be produced as far as the data allow. However there are many factors that relate to management, organization and culture that cannot be clearly included as "events". The same can also be said for many physical degradation processes which affect systems (including gearboxes), for instance; wear, corrosion and fatigue. The actual failure itself may be an "event", but there is a whole process that leads up to it, with many different influences.

The ID approach to system reliability assessment is a detailed probabilistic safety assessment technique that represents the factors influencing reliability of the system under study. A generic model of accident causation was proposed by Embrey (1992) which showed a combination of Event and Likelihood/Influences layers, see Figure 1. This approach, entitled MACHINE ${ }^{1}$ featured two distinct layers, namely Event layer and Likelihood (Influence) layer, hence the term Event-likelihood model (Kumamoto and Henley 1996).

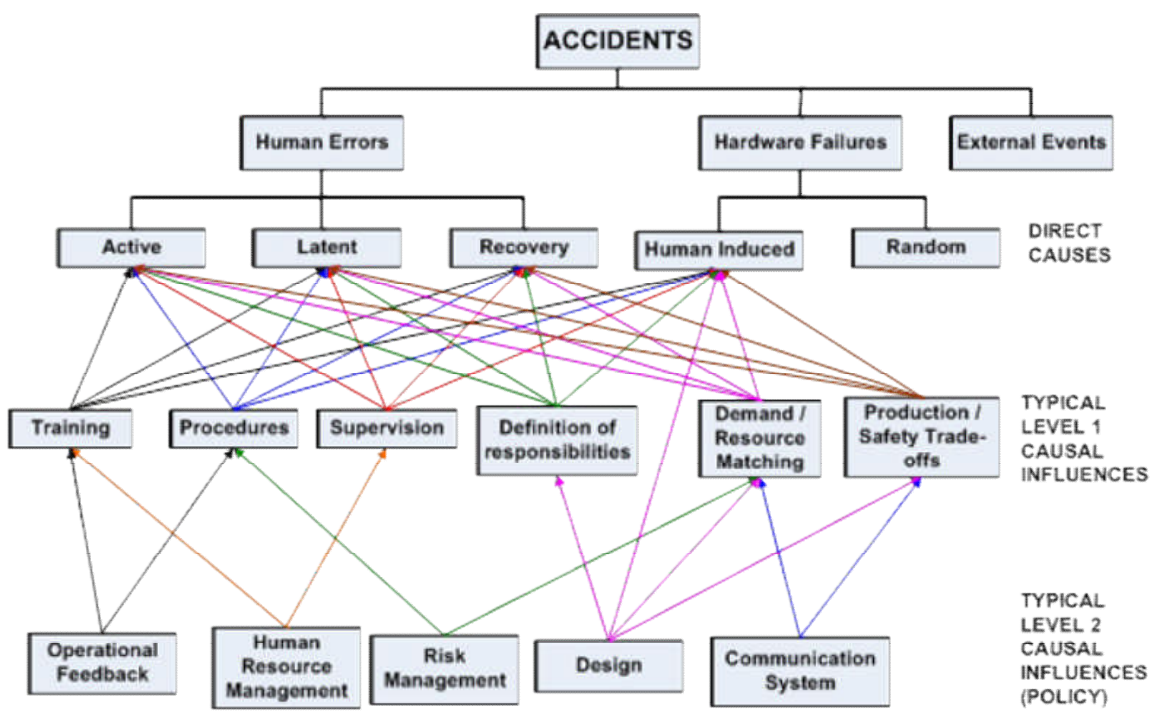

Figure 1 - Generic Influence Diagram model for accident causation (Embrey 1992)

As Figure 1 indicates, the ID concept is introduced to tackle multi-dimensional complex problems which involve internal mutual interference of factors that collectively produce a single overall event. It works to link qualitative description of complex technical problems, and their quantitative specifications. This approach "can serve the three levels of specification of relation, function, and number" (Embrey 1992) of involved factors, and it works in both deterministic and probabilistic cases.

Hokstad et al, 1999, Hokstad et al 2001, Herrera et al. 2010, used the ID approach to assess risks associated with operating helicopters over the North Sea. The approach, with its ability to

\footnotetext{
${ }^{1}$ Model of Accident Causation using Hierarchical Influence Network Elicitation
} 
represent both technical and management issues, can be used for assessing reliabilities of a wide variety of systems. A further example is in the domain of Air traffic management in which an Integrated Risk Picture was created (Eurocontrol, 2006). This used a combination of Fault tree analysis and ID to estimate risk due to errors that can influence five different accident types. More details on the development and use of IDs are available within these references. Detailed ID mathematical model is given by (Embrey 1992) for further reference as well.

The MGB lubrication system designs of various helicopter types are different with respect to component layout, structures, redundancy and detailed performance specifications. This variation in designs emphasizes the need for a generic model to accommodate the differences between designs. This study introduces such a generic ID component-based model. The approach taken allows more flexibility than other techniques that are available e.g. fault tree analysis, and can easily be reconfigured in the light of new information or data.

\section{METHODOLOGY}

This paper reports on a method for assessing the reliability of pressurized lubrication systems, and summarises the dominant failure modes. The Influence Diagram approach was applied to investigate the reliability of the MGB pressurized lubrication system, and the role each subsystem component may play to influence the overall reliability. Three main activities are conducted and discussed within this research and Figure 2 illustrates the sequence of the work. Results obtained from these activities are discussed to set the basis for both prevention and mitigation techniques in regard to MGB lubrication system failure.

i. Literature review covering aspects of MGB design and architecture, lubrication, failure diagnostics and prognostics, reliability and testing.

ii. Determination of MGB lubrication systems failure triggers and failure modes, and other failure contributing factors through fault trees analysis, and by consulting industry experts.

iii. Investigation of the MGB lubrication system reliability at the sub-system level using ID concept.

Within the current research, an ID model is formulated to evaluate the effect of different design and maintenance factors on the overall performance of the MGB oil system. The aim is to introduce a generic tool, based on authenticated evidence, which can be used to evaluate the helicopter MGB lubrication system at a given set of inputs. A failure is considered to have occurred if any of the associated factors (events, conditions, or influences) exist at any given time during the MGB lubrication system operation.

Once the model is constructed, simulations can be performed to assess the relative impact of the underlying factors. This simulation is demonstrated in the paper using two underlying, or so-called "Primary factors", namely Maintenance procedures and Human error. The respective influence factors have been estimated for the demonstration of the model's functionality. 


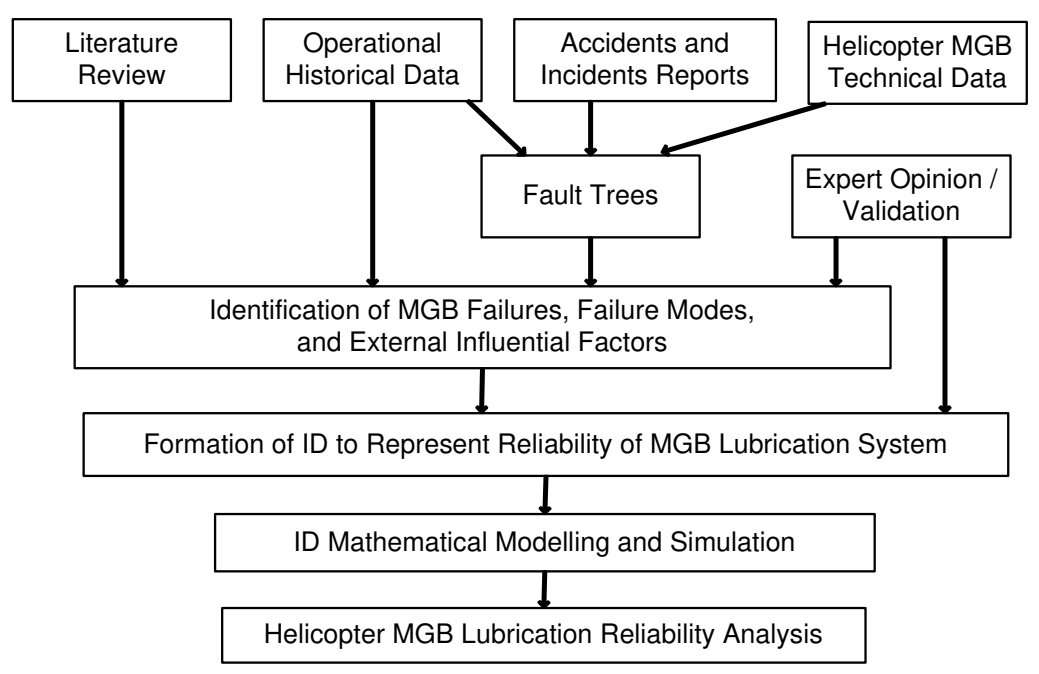

Figure 2 Research methodology - Sequence of activities

The pressurized lubrication system of helicopter MGB can be represented by three interlinked functions, namely lubrication of moving component, dissipation of heat produced due to friction and monitoring of the lubrication system. Accordingly, for the purposes of this study, a failure of the MGB lubrication system is considered to have occurred if at least one of these three functions fails. The latter can fail, individually or collectively, in four ways:

i. Inadequate quality of the MGB lubrication system oil.

ii. Inadequate quantity of the MGB lubrication system oil.

iii. Inadequate pressure value of the MGB lubrication system oil flow.

iv. Failure of the facility for providing monitoring, caution, or warning information regarding the MGB lubrication system operation.

\section{MAIN GEARBOX SYSTEM FAILURES}

\subsection{MGB design and failure aspects}

Literature rarely identifies detailed mechanisms for MGB lubrication system failures as per their root causes or modes of occurrence. Astridge (1989) performed detailed analysis of accidents and found the rotor-transmission (RT) system to be a major source of airworthiness related accidents and unreliability. Gears, lubricating system components, bearings and freewheels are the major risk-associated internal parts of the transmission. Astridge summarised the key MGB and lubrication system design features as:

\section{$\underline{\text { Data from accident reports }}$}

i. Oil recirculation with redundancy / emergency features.

ii. Minimization of pipework external to the gearbox,

iii. Effective oil content measurement.

iv. Oil filtration and wear debris capture provisions.

v. Tooth design for spiral bevel gears to ensure gear separation (not pulling into mesh).

vi. Solid ground spacers or shims are preferred to soft aluminum laminated shims.

vii. Effective means for detecting bearing roller contact fatigue 


\section{$\underline{\text { Data from overhaul information }}$}

i. Importance of adequate condition monitoring of MGB parts during overhauls.

ii. Corrosion of gears, bearings and shafts.

iii. Micropitting of gears teeth

iv. Debris damage (crater in raceways) caused by rolled-in debris.

v. Sight glass staining.

vi. Human error.

In the analysis sequence, the events were traced in detail from their origins until the point at which the MGB lubrication system ceased operation. The output of this analysis helped to understand the various failure scenarios and mechanisms that the MGB lubrication system can suffer as a result of different inputs (e.g. design errors, mechanical failures, oil quality, human inputs etc). This analysis has been used to design the influence diagrams to represent the problem being studied.

\subsection{Determining primary and secondary failures of MGB oil system}

A thorough search of relevant helicopter accidents and incidents formal reports involving MGB lubrication systems was conducted via various available databases and other data sources. A total of 10 reports were selected out of initial screening input of 1232 reports from sources shown in Table 1.

Table 1 - Data mining of helicopter accidents formal reports: screening and selection process

\begin{tabular}{|l|c|c|c|}
\hline \multicolumn{1}{|c|}{ Authority } & $\begin{array}{c}\text { Reports from } \\
\text { initial screening }\end{array}$ & $\begin{array}{c}\text { Reviewed } \\
\text { reports }\end{array}$ & $\begin{array}{c}\text { Reports } \\
\text { selected for analysis }\end{array}$ \\
\hline AAIB (UK) & 206 & 55 & 4 \\
\hline TSB (Canada) & 115 & 15 & 4 \\
\hline ATSB (Australia) & 179 & 23 & 1 \\
\hline NTSB (USA) & 713 & 78 & 1 \\
\hline BEA (France) & 16 & 16 & \\
\hline Others & 3 & 3 & 10 \\
\hline Total & 1232 & 190 & \\
\hline
\end{tabular}

Ten selected reports were analyzed using fault tree methodology to identify primary and secondary modes of failure of the MGB lubrication systems. The basic aim of performing this fault tree analysis was to get detailed understanding of triggers, causes and event sequences for these accidents and incidents. The analysis showed that although some similarities exist in some events, the overall sequence, nature and importance of each event was found to be different. In the analysis sequence, the events were traced in detail from their origins until the point at which the MGB lubrication system ceased operation.

The output of this analysis helped to understand the various failure scenarios and mechanisms that the MGB lubrication system can suffer as a result of different inputs (e.g. design errors, mechanical failures, oil quality, human inputs etc). The analysis has been used to design the influence diagrams to represent the problem being studied. A detailed listing of the primary and secondary failures and faults found through this analysis is given in Table 2. 
Table 2 - Primary and secondary failures and faults based on selected MGB oil system accidents and incidents

\begin{tabular}{|c|c|c|c|c|}
\hline Case & Description & Primary failures / faults & Secondary failures / faults & Effects / External qualifiers \\
\hline 1 & $\begin{array}{l}\text { Total loss of MGB oil } \\
\text { due to failure of oil filter } \\
\text { bowl. }\end{array}$ & Galling of the titanium studs & $\begin{array}{l}\text { Fracture of first stud, followed by second stud } \\
\text { and loss of MGB oil from oil filter bowl. }\end{array}$ & $\begin{array}{l}\text { Increased removal / installation cycles of studs. } \\
\text { Improper pre-load installation of studs. } \\
\text { Increased cyclic loads on studs during flight. }\end{array}$ \\
\hline \multirow[t]{5}{*}{2} & \multirow[t]{5}{*}{ Failed MGB oil pump } & \multirow[t]{3}{*}{ Oil pump idler gear seized. } & $\begin{array}{l}\text { Oil pump drive shaft separated at mid span } \\
\text { (Overstressed in torsion). Power to oil pump lost }\end{array}$ & Total loss of MGB oil pressure \\
\hline & & & $\begin{array}{l}\text { High temperature overstress damage of teeth of } \\
\text { combining gearbox input gears (from engines). }\end{array}$ & $\begin{array}{l}\text { Continued MGB operation after loss of oil } \\
\text { pressure. }\end{array}$ \\
\hline & & & MGB - Engine combining gearbox failed (Torque d & tive to MGB bevel gear is reduced) \\
\hline & & \multirow[t]{2}{*}{ Incorrect human input } & $\begin{array}{l}\text { MGB low oil pressure indicator bulb was } \\
\text { removed before flight }\end{array}$ & Human individual and organizational errors \\
\hline & & & $\begin{array}{l}\text { No oil pressure readings were provided to pilot (Se } \\
\text { was not implemented) }\end{array}$ & ice Bulletin to install a MGB oil pressure gauge \\
\hline \multirow[t]{4}{*}{3} & \multirow{4}{*}{$\begin{array}{l}\text { Normal flow of MGB oil } \\
\text { obstructed due to } \\
\text { incorrect positioning of } \\
\text { input quill bearing } \\
\text { housing }\end{array}$} & \multirow[t]{4}{*}{$\begin{array}{l}\text { Incorrectly installed } \mathrm{MGB} \\
\text { input quill bearing }\end{array}$} & $\begin{array}{l}\text { Bearing housing rotated } 90 \text { degrees clockwise in } \\
\text { relation to MGB oil input and output ports) }\end{array}$ & Multiple maintainer errors \\
\hline & & & No oil flow to MGB input quill bearing & \\
\hline & & & $\begin{array}{l}\text { High temperature skewing failure of input quill } \\
\text { bearings (parts jam when cage fails). }\end{array}$ & $\begin{array}{l}\text { Continued MGB operation with no oil flow to } \\
\text { bearing. }\end{array}$ \\
\hline & & & Sudden stoppage of main gearbox. & \\
\hline \multirow[t]{4}{*}{4} & \multirow{4}{*}{$\begin{array}{l}\text { Seizure of MGB pinion } \\
\text { outer bearing due to oil } \\
\text { starvation }\end{array}$} & \multirow[t]{4}{*}{$\begin{array}{l}\text { Debris dropped into the MGB } \\
\text { oil gallery }\end{array}$} & $\begin{array}{l}\text { Oil gallery feeding the outer bearing of MGB } \\
\text { input pinion was blocked }\end{array}$ & Multiple human individual errors. \\
\hline & & & No oil flow to MGB input pinion bearing & \\
\hline & & & $\begin{array}{l}\text { High temperature skewing failure of input pinion } \\
\text { outer bearing (bearing parts jam when cage fails). }\end{array}$ & $\begin{array}{l}\text { Continued MGB operation with no oil flow to } \\
\text { bearing. }\end{array}$ \\
\hline & & & $\begin{array}{l}\text { Intermittent binding of MGB input pinion outer } \\
\text { bearing }\end{array}$ & Intermittent stoppage of the MGB. \\
\hline \multirow[t]{7}{*}{5} & \multirow{7}{*}{$\begin{array}{l}\text { Failure of MGB rear } \\
\text { bearing } \\
\text { inadequate lubrication }\end{array}$} & \multirow{7}{*}{$\begin{array}{l}\text { Low Quantity of MGB oil was } \\
\text { available before flight start. }\end{array}$} & Poor lubrication of the rear MGB bearing & Human individual error \\
\hline & & & $\begin{array}{l}\text { High temperature skewing failure of rear MGB } \\
\text { bearing (bearing case broken) }\end{array}$ & $\begin{array}{l}\text { Continued MGB operation with no oil flow to } \\
\text { bearing. }\end{array}$ \\
\hline & & & \multicolumn{2}{|l|}{ Rear MGB bearing seized (rollers jammed sideways) } \\
\hline & & & \multicolumn{2}{|c|}{ Output pinion shaft turning in the inner race of seized rear bearing produced high temperature } \\
\hline & & & \multicolumn{2}{|c|}{ Hardened skin of the pinion shaft was softened; Slackness of shaft produced multiple fatigue cracks } \\
\hline & & & \multicolumn{2}{|c|}{ Fracture in torsion of the MGB pinion shaft at rear end of the MGB } \\
\hline & & & \multicolumn{2}{|c|}{ Damage to the flexible coupling at the forward part of the tail drive shaft } \\
\hline
\end{tabular}




\begin{tabular}{|c|c|c|c|c|}
\hline Case & Description & Primary failures / faults & Secondary failures / faults & Effects / External qualifiers \\
\hline \multirow[t]{3}{*}{6} & \multirow{3}{*}{$\begin{array}{l}\text { Loss of MGB oil due to } \\
\text { MGB case rupture }\end{array}$} & \multirow[t]{3}{*}{ MGB outer case fracture } & \multicolumn{2}{|l|}{ Loss of MGB oil pressure } \\
\hline & & & Extensive leak (loss) of MGB oil & $\begin{array}{l}\text { Failed 2nd stage epicyclic planet gear. Non-oil } \\
\text { system failure. }\end{array}$ \\
\hline & & & Loss of MGB oil pressure & \\
\hline \multirow[t]{2}{*}{7} & \multirow[t]{2}{*}{$\begin{array}{l}\text { Loss of MGB oil due to } \\
\text { MGB case rupture }\end{array}$} & \multirow[t]{2}{*}{ MGB input casing fracture } & Extensive leak (loss) of MGB oil & $\begin{array}{l}\text { Failed } 1^{\text {st }} \text { stage of No. } 1 \text { spur gear. Non-oil } \\
\text { system failure. External technical and human } \\
\text { inputs }\end{array}$ \\
\hline & & & Fracture of first stud. & \\
\hline \multirow[t]{3}{*}{8} & \multirow[t]{3}{*}{$\begin{array}{l}\text { Total loss of MGB oil } \\
\text { due to fracture of oil } \\
\text { filter bowl. }\end{array}$} & \multirow[t]{3}{*}{ Galling of the titanium studs } & Fracture of second stud. & $\begin{array}{l}\text { Stud was repaired just before the flight } \\
\text { Increased removal / installation cycles of studs. } \\
\text { Increased cyclic loads on studs during flight. }\end{array}$ \\
\hline & & & Loss of MGB oil from oil filter bowl. & $\begin{array}{l}\text { Increased load on the } 2^{\text {nd }} \text { stud } \\
\text { Increased removal / installation cycles of studs. } \\
\text { Increased cyclic loads on studs during flight. }\end{array}$ \\
\hline & & & The bearing adjacent carbon seal broke down. & \\
\hline \multirow[t]{7}{*}{9} & \multirow{7}{*}{$\begin{array}{l}\text { Failure of the plain } \\
\text { bearing in the main } \\
\text { gearbox cover for the } \\
\text { number } 1 \text { input pinion. }\end{array}$} & \multirow{7}{*}{$\begin{array}{l}\text { The plain bearing in the main } \\
\text { gearbox cover for the number } \\
1 \text { input pinion failed }\end{array}$} & \multicolumn{2}{|l|}{ Bearing lost lubrication (grease), and disintegrated. } \\
\hline & & & \multicolumn{2}{|l|}{ Oil spray out from the MGB on to the pinion shaft } \\
\hline & & & \multicolumn{2}{|c|}{ The number 1 pinion rapidly overheated and weakened. } \\
\hline & & & Local fire started at base of transmission & $\begin{array}{l}\text { Continued MGB operation after loss of oil. } \\
\text { Rotational imbalance due to bearing fracture. }\end{array}$ \\
\hline & & & \multicolumn{2}{|l|}{ Fracture of the No 1 pinion. } \\
\hline & & & Malfunction of the No. 1 free wheel unit & \\
\hline & & & Wear of internal parts of IFWU & \\
\hline \multirow[t]{3}{*}{10} & \multirow{3}{*}{$\begin{array}{l}\text { The input freewheel unit } \\
\text { (IFWU) and drive shaft } \\
\text { assembly failed. }\end{array}$} & \multirow{3}{*}{$\begin{array}{l}\text { Contamination suspended } \\
\text { and trapped in the lubricating } \\
\text { oil of the MGB input free } \\
\text { wheel unit (IFWU) }\end{array}$} & MGB IFWU failed. & $\begin{array}{l}\text { Repeated heavy lift operations. } \\
\text { Inadequate human input (maintenance) }\end{array}$ \\
\hline & & & Failure of drive to MGB & \\
\hline & & & & \\
\hline
\end{tabular}




\section{RELIABILITY ASSESSMENT OF GEARBOX LUBRICATION SYSTEM}

\subsection{Development of Influence Diagram}

It is challenging to set weightings to the impacts of each type of failure on each of the MGB functions. This is due to the complex nature of the mechanisms through which there failure type initiate and propagate. For instance a single event of oil loss from the lubrication system can trigger almost all of the four types of failure to varying degrees. The MGB lubrication system ID model is constructed from various resources, including:

- Relevant helicopter MGB's design specifications and architecture, with emphasize on lubrication system components

- MGB lubrication system related formal accident reports.

- Findings of relevant accidents analyses using fault tree technique.

- Published literature on MGB lubrication system designs, structures, and failure modes.

- Published literature on gearbox lubrication and gear failure diagnostics and prognostics

- Industry consultation and expert opinion.

The ID model for helicopter MGB lubrication system function failure analysis is given in Figure 3. The factors and inter-relationships shown have been identified from detailed study of accident reports and other technical sources. MGB lubrication system failure is the main event (Level A) triggered by the occurrence of any or all of the four main failure types of the lubrication system (Level B). The latter are influenced by 10 main influencing factors at level $\mathrm{C}$, and below this at level $\mathrm{D}$, a total of 15 primary factors exist which are the initial failure triggers. This level generally lists the overall components of the MGB lubrication system, in addition to the influences of human individual and organizational behaviour.

It should be noted that not all of the 15 Primary factors are of a purely technical nature. In fact the first one is the Maintenance procedures adopted for a given MGB lubrication system. This is a critical input to the integrity and operation of the system through both scheduled and reactive maintenance activities. Another external input to the MGB lubrication system reliability is the human activities carried on the system during maintenance or operation (e.g. walk-around checks errors). The evidence collected shows that both of these inputs play a significant role in the system reliability.

\subsection{Types of input to model}

The primary factors are represented at any given time by 15 different initial probability values which represent the likelihood of such factors occurring. The next step is the degree of influence that each of the primary factors on the relevant main factors of Level C. Subject matter experts could be employed for this important step, which is to gauge the relative importance of the varying factors. For this model, the three sources of input data are historical data of previous events, subject matter experts and simulated data

A similar process is adopted at all four levels of the model in Figure 3, with the inputs for each level being fed from the outputs from the level below. The model can further provide for other detailed analyses of the lubrication system as will be discussed in the following sections. 


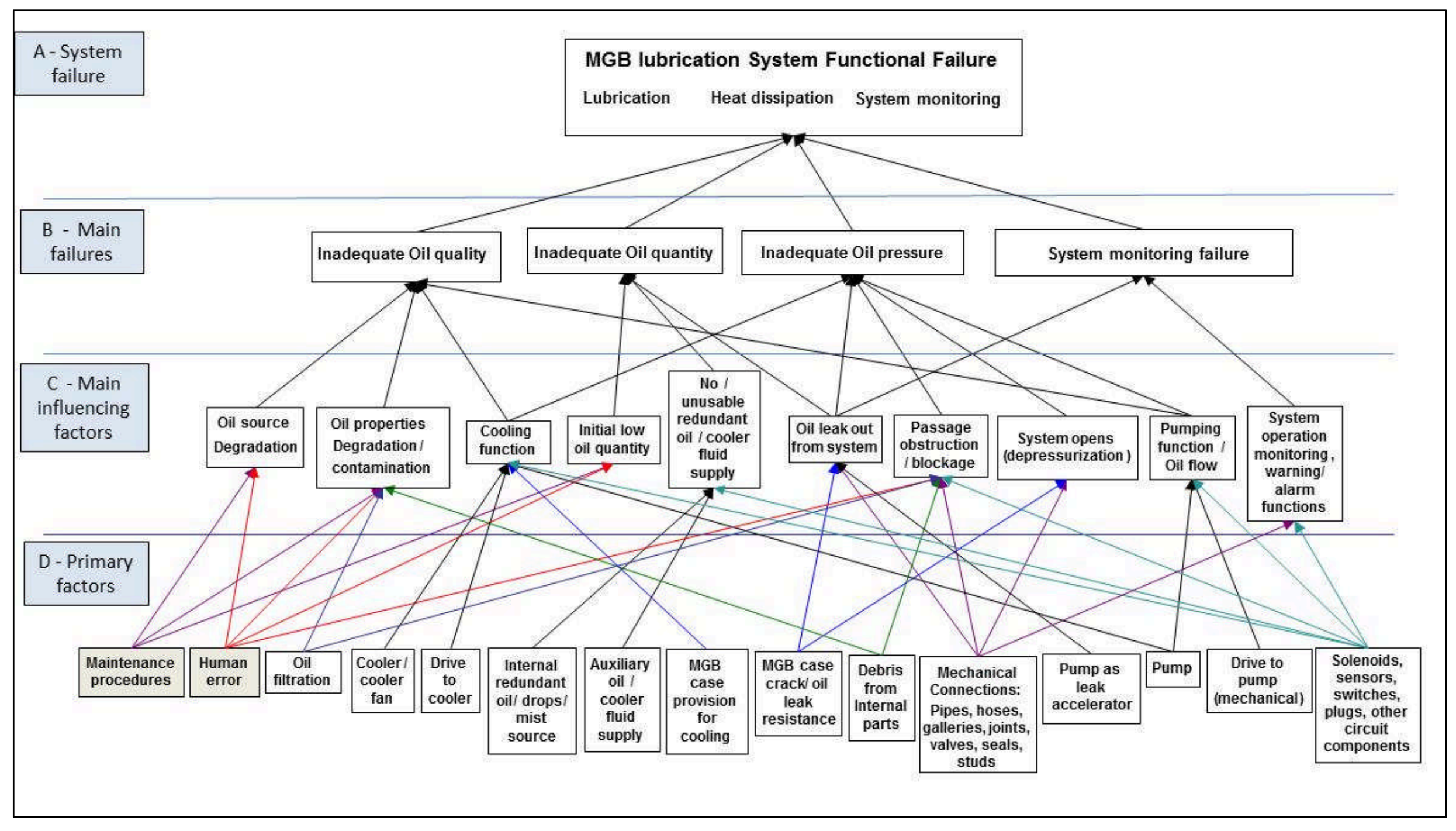

Figure 3 - Influence Diagram for helicopter MGB lubrication system function failure analysis 


\section{RESULTS}

\section{$5.1 \quad$ Component-based reliability analysis}

To demonstrate the model, one of the Main influencing factors at Level C examined is Oil source quality. The latter is influenced by two Primary factors, Maintenance procedures and Human error. For each set of influences, a truth table (Table 3) is set up based on the different combinations of contributory factors, using input probability values. This will give the different possible outcomes and the ensuing influence on the likelihood that Oil source quality will be compromised. In the first case, the probability of maintenance procedures being correct is 0.8 and the probability of no human error is 0.9 .

For this example these events are assumed to be independent, although it may be suggested that this need not be the case. Hence the combined probability of correct procedures and no human error is $0.8 \times 0.9=0.72$. In this case it is viewed that the influence factor is 0.1 , i.e. there is still a finite chance that despite correct maintenance procedures and faultless human actions, the oil source could still be degraded. The same process is adopted for the other three possible combinations. The influence factors may be changed depending on the prior knowledge of the program user, or other external data source.

Table 3 - Influencing factors for Oil Source quality

\begin{tabular}{|c|c|c|c|c|c|}
\hline \multirow{2}{*}{$\begin{array}{c}\text { Maintenance procedures } \\
\text { Input probability }\end{array}$} & \multicolumn{2}{|c|}{$\begin{array}{c}\text { Human error } \\
\text { Input probability }\end{array}$} & Influence factor & Prob of poor quality \\
\cline { 5 - 6 } Correct & 0.8 & Does not occur & 0.9 & 0.1 & $0.8 \times 0.9 \times 0.1=0.072$ \\
\hline Correct & 0.8 & Does occur & 0.1 & 0.3 & $0.8 \times 0.1 \times 0.3=0.024$ \\
\hline Incorrect & 0.2 & Does not occur & 0.9 & 0.7 & $0.2 \times 0.9 \times 0.7=0.126$ \\
\hline Incorrect & 0.2 & Does occur & 0.1 & 0.9 & $0.2 \times 0.1 \times 0.9=0.018$ \\
\hline \multicolumn{7}{|c|}{ The probability of the Oil source being poor quality is } & Sum of above =0.24 \\
\hline
\end{tabular}

\subsection{Analysis results}

The effects of occurrence of a failure to any one of the MGB oil lubrication system components or other influential triggers (the 15 primary factors) may be studied individually by varying the input test probability from $\mathrm{P}=0$ (factor does not occur) to $\mathrm{P}=1$ (factor is certain to occur) while keeping probabilities of all other factors as zero. In this manner, the output of the model will show the influence of each factor in turn. The following highlights the effects of the primary factor Maintenance procedures on MGB lubrication system. The sequence of testing is carried out as follows:

i. All input test probabilities for the 15 primary factors are put at zero value except for the Maintenance procedures factor which is assigned a value for input test probability that varies from $\mathrm{P}=0$ to 1 , with increment of 0.1 .

ii. Values of main factors (Level C), main failures (Level B) and system failure (Level A) are calculated at each of the input values for Maintenance procedures factor. 
iii. Only events directly influenced by the Maintenance procedures will change values as its input test probability is gradually increased. Other events are not influenced and continue to be represented at zero values.

iv. Influences on levels C, B, and A are described by Figures 4, 5 and 6 respectively.

The maintenance procedures greatly influence both the Oil source degradation and the Inadequate oil quantity main factors. Figure 4 shows how the probability of Oil source degradation increases from 0 to 0.7 as the input probability is varied between 0 and 1 . The Maintenance procedures also influence the Oil contaminated main factor but to a lesser degree. This is logical since the oil degradation even occurs due to many factors other than the maintenance procedures (see model in Figure 3).

The model links Oil source degradation and Inadequate oil quantity with two factors from level D (i.e. maintenance procedures and human factors), thus the share of influence of each of these two factors is high. This may be compared with the overall influence imposed over the Oil contaminated factor which is shared between four factors - Maintenance procedures, Human error, Oil filtration and Oil debris.

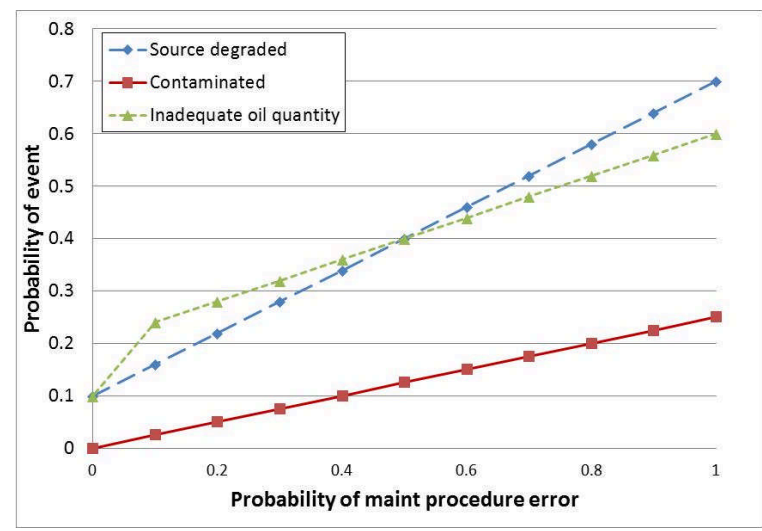

Figure 4 - Influence of 'Maintenance procedures' on main influencing factors

The results from level $\mathrm{C}$ are then used in the model to generate results at level $\mathrm{B}$, as shown in Figure 5. The initial causal factor Maintenance procedures influences two main failures, namely Inadequate oil quality and Inadequate oil quantity. In this representation, neither the oil pressure nor monitoring functions are affected directly by the maintenance procedure. The graph shows the probability for the two events increasing at different rates due to the different influence parameters used in the model. 


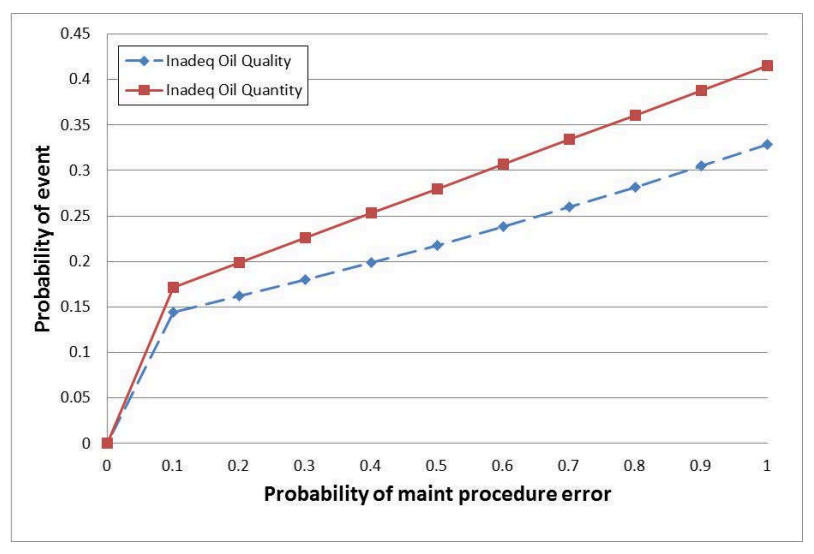

Figure 5 - Influence of 'maintenance procedures' on main failures

In the final step, Figure 6 shows the increasing influence of the maintenance procedures on the overall lubrication system reliability (level A). As the input test probability of Maintenance procedures is varied from 0 to 1 , the overall lubrication system failure probability increases up to a maximum value of 0.23 . Even with a probability of one, defective maintenance procedures do not lead to a corresponding certainty of lubrication failure due the variety of other factors in play. Likewise the occurrence of a maintenance error (not shown here) would not necessarily cause a total system failure.

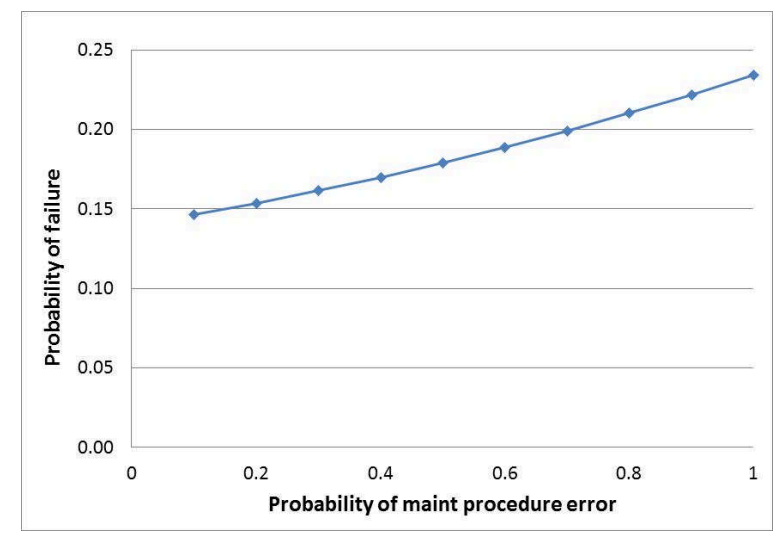

Figure 6 - Influence of 'Maintenance procedures' on the probability of system failure

\section{DISCUSSION AND CONCLUSIONS}

This work has introduced an influence type model which may be used to evaluate the key factors which contribute to MGB reliability. The fifteen primary factors have been selected based on incident and accident reports, and an initial demonstration presented. Further work will allow the model to be validated against in-service data, and generate sensitivity studies to provide benefit to a variety of users. A design organisation can use it to weigh the relative merits of different design proposals, e.g. installing back-up lubrication system, improving gear integrity or changing oil specification. A regulatory authority could use this model as a means of providing oversight of certification of gearbox lubrication systems. A helicopter maintenance organisation could use such a model to assess the impact of maintenance procedures and human factors on the overall system reliability. 
In this paper, an example of model output is presented based on simulated data using just one of the 15 primary factors. Further work is continuing to exercise and test the model to gain additional insights into the factors that affect the lubrication system. In this way it will be possible to "rank" the factors in order of priority (or influence) on the overall system. For example, it would be useful to know which factors are the most important e.g. lubricant viscosity, design features, maintenance frequency etc.

The ID approach has considerable merit since changing any of the parameters of the system can have multiple "knock-on" effects. It will be possible to feed in other forms of data, rather than simple (fixed) probability values, e.g. bearing reliability from Weibull analysis or fatigue data for mechanical components. Hence the model will develop to be of great use to a variety of users, and for a variety of purposes in the improvement of lubrication system reliability.

\section{Acknowledgement}

This work was supported by the European Aviation Safety Agency under Research Project EASA.2011/5.

\section{References}

Astridge D G (1989) Helicopter transmissions - design for safety and reliability. Proceedings Institution of Mechanical Engineers Part G Journal of Aerospace Engineering 203: 123-138

Astridge D G (1996) Design safety analysis of helicopter rotor and transmission systems. Proceedings Institution of Mechanical Engineers Part G Journal of Aerospace Engineering, 210: 345-355.

EASA (2012) Certification Specifications for Large Rotorcraft (CS-29) Amendment 3. Section CS.29.927. Page 1-E-5. European Aviation Safety Agency.

Embrey D E (1992) Incorporating management and organizational factors into probabilistic safety assessment. Reliability Engineering and System Safely. 38: 199-208.

Eurocontrol (2006) Methodology Report for the 2005/2012 Integrated Risk Picture for Air Traffic Management in Europe, Eurocontrol.

Herrera I, Håbrekke S, Kråkenes T, Hokstad P, Forseth U (2010) Helicopter Safety Report 3, SINTEF Report No SINTEF A15753.

Hokstad P, Jersin E, Hansen G K, Sneltvedt J and Sten T (1999) Helicopter Safety Report 2, SINTEF Report No SINTEF38 A99423.

Hokstad P, Jersin E, Sten T (2001) A risk influence model applied to North Sea helicopter transport. Reliability Engineering and System Safety. 74: 311-322.

Howard R A, Matheson J E (2005) Influence diagrams. Decision Analysis. 2(3): 127-143.

Kumamoto H \& Henley E J (1996), Probabilistic Risk Assessment and Management for Engineers and Scientists, IEEE Press 2nd Edition (1996).

Savage M, Radil K C, Lewicki D G and Coy J J (1988). Computerized Life and Reliability Modelling for Turboprop Transmissions, AIAA/ASME/SAE/ASEE 24th Joint Propulsion Conference, Boston AIAA-88-2979.

TSB (2010) Main Gearbox Malfunction/Collision with Water Cougar Helicopters Inc. Sikorsky S-92A, C-GZCH. St. John's, Newfoundland and Labrador, 35 nm E. 12 March 2009. Report Number A09A0016. Transport Safety Board of Canada. 
2015-02-19

Reliability model for helicopter main gearbox lubrication system using influence diagrams

\author{
Rashid, Hamad
}

Elsevier

Rashid HSJ, Place CS, Mba D, et al., (2015) Reliability model for helicopter main gearbox lubrication system using influence diagrams. Reliability Engineering and System Safety, Volume 139, July 2015, pp. 50-57

https://doi.org/10.1016/j.ress.2015.01.021

Downloaded from Cranfield Library Services E-Repository 